\title{
New Ways for Learning and Knowledge Transfer Using Social Semantic Technologies
}

\author{
Gisela Granitzer ${ }^{1}$, Armin Ulbrich ${ }^{1}$, Klaus Tochtermann ${ }^{12}$ \\ and Reinhard Willfort ${ }^{3}$ \\ ${ }^{1}$ Know-Center Graz, ${ }^{2}$ Graz University of Technology, ${ }^{3}$ Innovation Service Network \\ Austria
}

\section{Introduction}

The history of technology enhanced learning has started about 15 years ago. But it kicked off far earlier if we consider early learning machines such as the one developed by F.B. Skinner as technology. All technology developments have been accompanied by conceptual developments. In the beginnings, the notion of technology enhanced learning was to provide standardized learning material using monolithic systems, referred to as learning management systems. But this was just a one way provision with an author on the one side and a consumer, the learner, on the other. Sometimes technology enhanced learning consisted of simple websites containing content intended for learning. Today we find service-based collaborative modular systems. But not only technologies have changed. Also the concept of learning has gone through various changes. Originally, learning was very much dominated by its formal character, while in the meantime informal learning has evolved as a more promising way to learn. It was the paradigm shift from behaviourism to cognitivism and to constructivism which has triggered this change, which was further accelerated through the new technology developments (Tochtermann \& Granitzer, 2008).

The importance of technology enhanced learning is also well documented by European Research Programmes (Framework Programmes 6 and 7). One of the reasons why corresponding research has been heavily supported by the European Commission lies in the fact that the change of working condition and the high-speed evolution of information and communication technologies, peoples' knowledge and skills need continuous up-dating1. For the current 7th Framework Programme, challenge 4 Digital Libraries and Content explicitly mentions in its working documents that the challenge, therefore, is to harness the synergies made possible by linking content, knowledge and learning ${ }^{2}$.

Both statements support our notion that learning is more than consuming defined content in order to reach a pre-defined learning goal. Instead, it is more about continuously acquiring, generating, applying and even sharing knowledge and not so much about conscious and intended consumption of content.

\footnotetext{
${ }^{1}$ http:/ / cordis.europa.eu/ist/telearn/index.html

2 http:/ / cordis.europa.eu/ist/kct/fp7-challenge4-excerpts.htm
} 
Thus, the emphasis of this contribution is on supporting new ways of knowledge transfer, with a special focus on supporting knowledge activities directly at the work-place in accordance with the current needs of the employee - or as we will call them throughout the remainder of this paper - the knowledge worker. In our opinion, solutions which support the knowledge worker on demand reach from simple applications to complex systems. In chapter 2 we briefly introduce the need for workplace learning and knowledge transfer. How knowledge transfer can be supported through Social Software, Semantic Technologies, and a combination of Social Software and Semantic Technologies, is discussed in chapter 3 , 4 , and 5, respectively. In chapter 6 we present our conclusions.

\section{Learning and Knowledge Transfer at the Workplace}

One success factor for efficient knowledge work is the availability of information relevant to a specific task at the time the knowledge worker needs it. As long as knowledge workers only use resources from their local working environment (e.g. her PC), they can produce good results, assumed that her personal knowledge management is good. But real life is more complicated. Even if the knowledge worker could exactly define her information needs, which often is not the case, she will encounter problems in finding what she needs to fulfil her information need. Usually corporate information is distributed among repositories, available in the intranet, the internet, and is even held by people. Every time the knowledge worker has information need, she has to interrupt her work to spend some time for searching the required information.

To better support knowledge workers, our vision is that of software systems ob-serving the activities of the knowledge worker, deriving their information needs, mining distributed resources and finally providing the knowledge worker with information relevant for her current situation. And this vision is about to become reality: In the European Project APOSDLE such a comprehensive software system is currently being developed and evaluated [http://www.aposdle.org]. But also smaller solutions exist which could support the employee in her daily work. For example, a Wiki can help with documenting working experience and providing knowledge shared among different people. Ontologies can help to better organize workplace related information. In our notion, the optimized next-generation workplace learning and knowledge transfer solutions, be it extended systems or single applications, will have three key features in common.

- $\quad$ Adaptation to current information needs

- Support of informal learning

- Detection of user context

In the following sections we will further justify and explain in depth these key features (Lindstaedt \& Ulbrich, 2006).

\subsection{Needs Orientation}

Normally, organizations are interested in maximizing the productivity of their employees. A study (Brakeley et al., 2004) with 244 executive managers showed that $69 \%$ of respondents judge measures for increasing employee productivity as the most relevant task of human resource management. Concerning training initiatives $77 \%$ of the respondents find it most important to align training with organizational goals and $75 \%$ state that learning contents 
match the needs of the employees. However, only $14 \%$ report satisfaction about the way how training is aligned with organizational goals and needs.

Workplace-integrated solutions can especially help concerning the orientation on learning needs, since needs oriented support is their philosophy. By providing the knowledge worker with resources matching her current requirements, knowledge acquisition is facilitated and thereby one central precondition for increased productivity is established.

\subsection{Informal Learning}

Another argument for workplace learning solutions comes from the role informal learning takes in working. Usually, employees apply less than $30 \%$ of the knowledge acquired in formal learning situations to their later everyday work (Robinson, 2003). About $80 \%$ of the knowledge needed for individual work is acquired in informal learning situations (Raybould, 2000), (Cross, 2007). The proportion of formal learning as opposed to informal learning is only about $10 \%-20 \%$ of learning at work (Cross, 2003). Obviously, informal learning is highly relevant in the context of knowledge transfer and acquisition. Hence, there should be corresponding support. These facts are also confirmed by the Business Intelligence Industry Report 2007 published in the Chief Learning Officer Magazine (CLO, 2007). Respondents estimated the percentage of informal learning to be up to $70 \%$. With this in line, there is also the intention to place more emphasis on informal learning. Even though classroom training was said to be the most widely used method, at least $40 \%$ of the respondents reported a decrease of this method during the last 12 to 18 months prior to the survey, and $72 \%$ and $62 \%$ expected an increase in asynchronous and synchronous eLearning, respectively.

Against this background workplace learning solutions are an interesting option. They aim at supporting knowledge workers in their informal knowledge transfer activities, even though supporting measures are organized through formal structures.

\subsection{Context Awareness}

As Cross states human conversation is the most powerful technology for knowledge transfer (Cross, 2007). Its power is based on the fact that in communication people usually adapt to their counterparts. Knowledge transfer happens according to the knowledge and experiences of the vis-à-vis. While a novice is given basic information helping to develop understanding, an expert is given extra information widening her knowledge horizon or providing inputs for reflection.

As said before, context detection is also considered to be one key feature of work-place learning solutions. By observing the behaviour of knowledge workers in the sense of used applications, visited websites, current tasks or processes, the context is detected and supporting content can be provided accordingly. When we talk about con-text, we distinguish among three context types: the domain context representing the topic in which work is embedded, the process context representing activities that cumulate to working processes and workflows, and the user context which refers to the knowledge worker herself. Concerning these contexts - in (Lindstaedt et al., 2005) the domain, process, and user context are summarized under the term 3spaces - various aspects such as competences, acquired knowledge, goals, roles, or tasks are distinguished. In (Jameson, 2001), (Klemke, 2002) and (Schmidt, 2004) different schemata have been described. 
In the following chapters 3,4 , and 5 we would like to give an idea about how latest technologies, namely Social Software, Semantic Technologies and the combination of them, Social Semantic Technologies, might be used for supporting the knowledge worker in her daily work. Each chapter starts with an introduction to the technology in question. Chapters 3 and 5 rely on use cases which are reported in scientific literature. Since Social Semantic Technologies are not a commonly used and applied solution yet, only scenarios, and no use cases about their potential utilization are sketched. Most of the use cases and scenarios meet the key features need and informal learning. To a lesser extent they address the key feature context. Also, the solutions are not necessarily machine-aided as the description of the key features might have suggested. However, we think that because of their relative simplicity they are of particular interest for small and medium sized companies that neither have the large number of users nor the amounts of content which machine-aided solutions usually require.

\section{Social Software}

\subsection{A Brief Introduction to Social Software}

About three years ago, technologies and concepts summarized under the term Web 2.0 emerged. Since then they have attracted increasing attention, not only for the private but also for the corporate sector. The term Web 2.0 was coined by Tim O'Reilly and colleagues when they prepared a web technology conference in October 2004. It should address the next generation of the world-wide web, a social web. The Web 2.0 is made up of services and users redesigning the web as a platform for these users and services. The term architecture for participation accurately describes the idea behind this. O'Reilly tries to define the Web 2.0 through eight design patterns: the long tail, data is the next intel inside, users add value, network effects by default, some rights reserved, the perpetual beta, cooperate do not control, software above the level of a single device (O'Reilly, 2007). In general, the Web 2.0 is built upon the three pillars content, community, and services, embraced by networking.

Web 2.0 can be seen from two perspectives. One perspective - and this was the basic idea refers to a business model. Enterprises that build upon the eight design principles belong to a new group of Internet based businesses. Web 2.0 undertakings are Xing, Salesforce, Innocentive, or 23andMe, just to mention a few. The other perspective also summarizes individual applications under the term Web 2.0. They need not necessarily make up the business model of an enterprise. Social Software is only a part of the Web 2.0 but sometimes used synonymously with it . Social Software supports and enables interpersonal communication, interaction and collaboration and it is characterized by a high degree of self-organization of the users involved. The idea behind Social Software is that users produce content and make it available free of charge and with new copyright models (e.g. creative commons) for reuse by other users. Wikis and Weblogs are the best known examples for Social Software. But Social Software goes far beyond these two applications. Also Internet Relay Chat, Internet Forum, Instant Messaging, Social Bookmarking, Social Media Sharing, Social Task Sharing, Social Networking Services and Engines, and even Massive Multiplayer Online Games can be classified as Social Software. 


\subsection{Social Software Applied to Learning and Knowledge Transfer}

While in the beginnings companies were reluctant to integrate Social Software in their business environment, many corporate best practice examples exist today. McAfee presents the results of a survey among students of an MBA class at Harvard Business School (McAfee, 2008). 50\% of the 36 students surveyed reported that they would introduce social applications such as bookmark sharing, networking or prediction markets. $44 \%$ reported that they would introduce Wikis and 22\% Blogs for accelerating setting-in of new employees, fostering cross-project, cross-department and even cross-company knowledge sharing and capturing and preserving organizational learning. In the following we outline three real-world examples. In each example the challenges are described and a Social Software solution addressing these challenges is introduced.

Training

Distributed sales organizations, e.g. in the automotive industry, face the challenge of holding their staff up-to-date on new car models, special campaigns or new technologies and of course related customer questions. Continuous training is needed but often not possible. Training requires travelling which means that employees are absent from work for some time. Sometimes costs for this absence even exceed training costs. Further problems consist in the well known fact that only fractions of the knowledge acquired in training are transferred to work. And even if transfer is successful, it is not sustainable.

For meeting these challenges the car manufacturer Opel (Magnus \& Hatz, 2008) decided to use Podcasts. The procedure of Podcast production was as follows. The Podcast team gathered information by calling sales staff, by analyzing training and seminars, or through media research. All the gathered information was documented in a Wiki. Important topics were selected for Podcast production which happened every two months in advance. The MP3 files were made accessible on a server for consumption on MP3 players, laptops, CDROM, or mobile devices. This most innovative idea for training was widely accepted among the participants. After the pilot phase $89 \%$ of participants judged the project as success; $83 \%$ found the medium appropriate. 94\% listened to each Podcast. Podcasts were consumed briefly after publication, and users listened to the Podcasts during work, at home, on their way to work, and some even during sports. Because of the great success of the pilot project a company-wide roll-out started in May 2007.

Leveraging employee knowledge

Today companies are under pressure to react immediately to upcoming trends and challenges. Since a wealth of knowledge lies inside their staff, an ambitious task is to leverage this knowledge, which of course is not that easy. Even though a lot of knowledge is documented explicitly, a huge amount remains implicitly in the heads of the people. Therefore it is often not clear who is an expert and thus can be asked for advice. And even if experts are known, their knowledge would be also interesting for all colleagues and not just the one who had the related knowledge deficit.

Namics AG, an IT and Web Service provider, applied the following approach (Hain \& Schopp, 2008) in order to leverage the knowledge of their employees. When someone had a question, she sent an email to all. People who could answer the questions replied there answer to all too. This of course resulted in a flood of emails out of which only a fraction was relevant and interesting for the employees. To meet this problem it was decided to introduce multiple Weblogs addressing different topics to which employees could subscribe. Weblog posts could be written within the Weblog software or an email could be sent to the 
Weblog. The employee who had a question could decide whether all colleagues should be informed by email about the post or if only subscribers should receive an email. Also the answer could be given by email which was sent to the Weblog and attached to the initial blog post. Since questions and answers were collected within one Weblog and related to each other, highly relevant and sustainable knowledge could be easily exported to a knowledge database for long term utilization. The main advantage of this solution was the introduction of the pull principle meaning that employees could decide which information they wanted to receive. Moreover, because of the easy assignment of provided information, author and experts could be better identified. A lesson learned from this project was that a solution should be attached to existing processes and that user acceptance and not technology should guide the selection of the solution.

Documenting and distributing key knowledge

Usually companies store their knowledge across various systems such as knowledge or content management systems, file systems, or other repositories. This results in common problems. Uploading is an additional effort for each user as is updating of the systems. Often the structures are not intuitive and might even be different for each department, not to mention information which is isolated and not linked to each other. Because of such difficulties employees tend to store their documents locally or on other systems than the dedicated system. Delays in or the impossibility of finding relevant information, decreases productivity and in turn weakens the competitiveness of a company.

The Inhouse Consulting Department of the Deutsche Bahn AG faced similar challenges (Mielke et al., 2008). Its main goal was to have a functioning knowledge management system where they could document and distribute a) knowledge relevant for the fast development of services, b) knowledge that was only available in individual employees or small groups of employees, and c) knowledge which could only be acquired with high personnel, time and financial efforts otherwise. In order to allow multiple perspectives on the knowledge base, the knowledge items should be linked to each other. Moreover, the system should be easy to use, should mimic a knowledge bazaar and not a static library, and should enhance communication among the employees. These requirements led to the selection of a Wiki as knowledge management system. In a sophisticated introduction process including change management measures the Wiki was successfully implemented.

Of course, the application of Social Software can go beyond supporting individual business processes within organizations. There are also examples where the entire business model is based on Social Software. Such an example is neurovation.net. This platform mainly supports the community based development of ideas. The individual user can post a challenge, invite other users to think about this challenge, and gets back ideas and solutions which she probably would not have been able to create her-self. How this platform works and how it was developed is outlined in (Stocker et al., 2008).

\section{Semantic Technologies}

\subsection{A Brief Introduction to Semantic Technologies}

Semantic Technologies refer, as the name suggests, to technologies which help giving meaning to data. Even though Semantic Technologies need not necessarily be tied to the Web, the first applications had their focus on Semantic Technologies for the Web for which reason we talk about the Semantic Web. Machine-processable data is at the centre of the 
Semantic Web. Because of its formal and coherent description, this data can be processed by machines in a meaningful way. For these purposes data must be application-independent, composeable, classified, and part of a larger information ecosystem according to (Daconta et al., 2003). Contrary to Social Software which mostly deals with social connections and human readable content, the Semantic Web deals with formal content and its formal connections. Three problems suggest that there is a need for Semantic Web technology.

- Today information overload is a common problem. The information quantity continuously increases, but the human information processing capacity does not. For that reason, it becomes more and more difficult to select relevant data and draw well informed decisions.

- $\quad$ Usually data are stored in monolithic systems, also called stovepipe systems. This raises difficulties when it comes to sharing data across databases. Searching and finding remain restricted to the individual systems. It is the work of people to connect and integrate data which yields dissatisfying results. This is a problem in every day work, but much more of a problem as regards security and surveillance.

- The need for content aggregation causes the third problem. Even though it can be done on an HTML basis, it is not yet possible to aggregate content concerning its meaning.

Humans of course can handle these problems, since they are able to filter, infer, map, and combine content, but only on a small scale. Machines cannot do that, even though principally they would have the capacity. And this is exactly the vision of the Semantic Web. According to this vision, machines will process information in a meaningful way with the meaning coming from a defined structure of the data. The main technologies which will empower machines »to understand the meaning of data « are XML, RDF, the corresponding schemata, and Ontologies. For a better understanding we will briefly introduce these concepts but not go into the details, since details are out of the scope of this contribution.

$X M L$

The eXtensible Markup Language (XML) has been recommended as a set of syntax rules for hierarchically structured data in 1998 by the World Wide Web consortium (W3C). The latest (fourth) edition of XML 1.0 has been published in $2006^{3}$. XML has originally been designed as a language for describing the structure and the syntactic elements of very large electronic publications such as manuals provided by aircraft manufacturers. In the meantime it has turned out that XML is at least equally well-suited for exchanging very small portions of information between different services on the Web.

A piece of data or document written in XML can automatically be examined if it first, conforms to a number of general construction rules for documents (i.e. if the document is 'well-formed') and if it second, conforms to a specific grammar, which has been designed for a given use case (i.e. if the document is 'valid'). XML can therefore be used for applications, which need to make sure that the information exchanged with third parties is predictable with respect to the document's structure and correct with respect to the document's syntax (cf. (Daconta et al., 2003)).

\footnotetext{
${ }^{3}$ http://www.w3.org/TR/2006/REC-xml-20060816/
} 


\section{$R D F$}

The Resource Description Framework (RDF) is a model for expressing 'sentences' made up of subject, predicate and object ${ }^{4}$. Technically speaking, these sentences are referred to as 'RDF triples'. RDF triples can be used to make factual statements about the subject of a sentence and express relationships between subjects and objects. An example for this would be the following sentence: ('Gisela Granitzer' 'is an author of' 'this article'). Typically, subjects, predicates and objects are codified as unique identifiers of remote resources in the form of so-called Uniform Resource Identifiers (URIs, e.g. http://www.know-center.at). Thus, virtually anything, which can be identified uniquely by an URI, can also be a part of an RDF statement (Daconta et al., 2003). Objects as well as predicates can be used as subjects in different statements which gives a net like structure, a so-called semantic net, that allows for drawing conclusions.

Ontologies

RDF lacks basically two properties: first, it does not provide means for stating to which class an RDF element belongs. And second, it does not provide language-inherent means to control how further information is inferred from assertions made via RDF triples. Both drawbacks are taken care of by further standards of the Semantic Web namely by the Resource Description Framework Schema (RDFS5) and the Web Ontology Language $\left(\mathrm{OWL}^{6}\right)$.

RDFS introduces the concept of classes. A class is a specification of attributes of an RDF element on an abstract level. RDF elements (subjects and objects) can be defined as belonging to a specific class. The concrete digital 'embodiment' of an RDF element, which belongs to a class, is called an instance. Predicates of an RDF triple can also be assigned to classes, although classes for predicates are labelled and treated differently in RDFS. The introduction of a class concept in RDFS makes it possible to conclude automatically that an instance belongs to some specific class based on the instance's properties. RDFS makes it also possible to infer what properties an instance must possess basing on the class to which the instance belongs. RDFS additionally introduces means to specify what classes the subjects (domain) and objects (range) of an RDF triple must belong to, given a certain predicate.

OWL enhances RDFS even further in that it introduces a number of new language constructs. In concrete OWL adds constructs for classes (e.g. cardinality, enumeration of instances, class membership based on the existence of certain property values), relations between classes (e.g. equivalency, transitivity and symmetry of predicates) and the construction rules of classes (e.g. classes, which are exactly the intersection of two other classes). These constructs have been designed such that they allow relating instances to each other by quantifiers and operators in a way that makes automatic reasoning (i.e. inferring further knowledge from existing statements) possible using tree-like logical rules. This is true for the sublanguage OWL DL, which corresponds to a field of logic labelled Description Logic (DL). The other two sublanguages of OWL are OWL Lite (less expressive than OWL

\footnotetext{
4 Please note that several different labels are used for the elements, which make up a triple. Since we find the 'sentence'-metaphor useful in the context of this work, we will stick to the label 'subject', 'predicate' and 'object' for the respective elements.

${ }^{5}$ http://www.w3.org/TR/rdf-schema/

${ }^{6}$ http:/ / www.w3.org/TR/owl-features/
} 
DL) and OWL Full (more expressive than OWL DL but statements are not necessarily logically decidable).

OWL, RDFS and RDF together are sufficient to make up an ontology upon which ontologyaware applications can be built. An Ontology in the context of this contribution is therefore a construct, which specifies how statements are made, what elements they can contain and what logical rules are defined in order to interpret statements properly for drawing further conclusions from them. A piece of software, which commits itself to a given ontology states that the outputs it produces via its computations are logically consistent with the specifications and rules of the ontology no matter how the data are represented by the software internally (Gruber, 2008).

\subsection{Semantic Technologies Applied to Learning and Knowledge Transfer}

This section describes examples in which semantic technologies provide a solution to challenges at the workplace. Each example includes a brief description of the challenge and introduces a solution based on semantic technologies. Details are not given, since the purpose is to give an idea and highlight that semantic technologies are meaningful instruments.

Competence matching

As it is stated in (Colucci et al., 2007), competencies held by human resources make up the core of knowledge intensive organizations. Personnel can be understood as knowledge ware-house. If required competencies are not available the organization has two options. One is to hire external personnel. The other is to build up the required competencies within the organization. In both cases the organization has to specify its needs and find resources that can satisfy the competency needs. In the understanding of that article the resources can consist in either external personnel or learning objects which help to build up the competencies in internal personnel. In order to satisfy a knowledge need, professional profiles and learning objects must be mapped to each other.

(Sicilia, 2005) introduces a very interesting approach to competency gap analysis based on ontological descriptions. Competencies are taken from established catalogues of competency descriptions such as $\mathrm{O}^{*} \mathrm{Net}$. They are on the one hand mapped onto professional profiles of job situations (organizational needs) and on the other hand onto employees' profiles (competency model of employee). Both profiles are constructed using an integrative ontological schema, namely a taxonomy of terms used for labelling competencies. Therefore professional profiles and employees' profiles are comparable and allow for inferring an employee's competency gap with respect to a given job situation. Moreover, competencies are related to each other according to their prerequisite-dependencies, thus allowing inferring a meaningful competency gap although competencies might not explicitly be addressed in either one of the profiles involved. (Ley et al., 2008) and (Ley et al., 2007) describe an ontology-backed approach on matching professional profiles and employees' learning history profiles in the domain of work-integrated learning. They enhance the approach shown above in that they apply an Ontology in OWL DL (not merely a taxonomy of terms) as a schema used in professional profiles as well as in persons' profiles.

Personal Information Management

For enhancing productivity and competitiveness personal information management is as crucial as corporate information management. The employee is dependent on finding and recalling information within her emails, files, contacts, bookmarks, and other resources 
(Sauermann et al., 2007). Of course there are categorization schemata such as file system or email folders, or tags. However, these schemata are keyword oriented, while cognitive models are more complex and not only based on taxonomies. For the knowledge worker it would be helpful to organize her information according to her individual mental model. Against this background, in (Sauermann et al., 2007) a framework for personal information models was developed. Based on RDFS as representation language multi layer Ontologies representing concepts and documents are used which are in the current attention of the user. Basic concepts such as time, place, people, organizations, and tasks are pre-modeled and can be extended by the user at will, to express their mental model. Items can be assigned to multiple concepts, extending the limitations of current hierarchical file system.

Retrieval of relevant information

Not only must organizations satisfy their competence needs or must employees organize their information in an optimal way, but also do knowledge workers depend on finding information, which match with their current information needs. According to the vision of the Semantic Web, retrieval can be optimized by the semantic enrichment of resources (Scheir et al., 2007). However, resources are sparsely annotated with semantic information. To bypass this problem semantics must be introduced differently. In (Scheir et al., 2007) associative retrieval is suggested for solving the problem. Associative retrieval comprises techniques which help to find information that is somehow associated with information already known to be relevant. It is based on the principle that starting from one node activation spreads across a network consisting of nodes and edges. Nodes that are tightly connected to the starting node are reached first and thus are most relevant compared to the starting node. In the described showcase some resources are annotated with concepts of a predefined Ontology, while others are not. Two layers were used, a document and a concept layer. Documents were connected to each other by text based similarity, and concepts were connected to each other by semantic similarity. Additionally, document nodes were connected to concepts nodes. So, if a query starts with a term matching a concept, starting from that concept the network is activated. Or if a query starts with a term only matching the text in a document, activation would spread over the network starting at that document.

\section{Social Semantic Technologies}

\subsection{A Brief Introduction to Social Semantic Technologies}

As the above descriptions show, the Web 2.0 can be associated with a human web, which in particular builds on user generated content and networks of people, while the semantic web constitutes a machine-readable web of data. In most recent years, however, one can observe an increasing convergence of social media and semantic systems to a Social Semantic Web (Pellegrini \& Blumauer, 2007), often also referred to as Web 3.0. There are two variations of the Social Semantic Web: Semantically Enabled Social Software and Socially Enabled Semantic Web (Pellegrini \& Blumauer, 2008). The first variation refers to the enhancement of Web 2.0 content by machine processable semantic data. The second variation refers to the collaborative creation of structured (semantic) data. Even though these two variations are conceptually different, they reflect only two sides of the same medal. In the following we will introduce some applications that can be summarized under the term Social Semantic Web. 
In the case of Semantic Wikis, the content of a Wiki is mapped to a predefined structure which machines can »understand «. The structure comes from RDF or OWL and goes beyond structured text and hyperlinks. Thereby content is enriched with metadata and relations and thus becomes processable by machines. Common features of Semantic Wikis include (Schaffert et al., 2006) annotated links connecting knowledge elements with the annotations stating the type of association between the elements. Since not only links but also knowledge elements carry metadata, content can be enriched by providing related content. Annotated links can also be searched which helps revealing how information elements are connected. In contrast, when searching for knowledge elements also connections are delivered. Some Semantic Wikis also integrate reasoning support services which deduce information which otherwise would remain hidden to the user.

Also Weblogs convene with Semantic Technologies in the form of structured and semantic blogging. Structured blogging means that machine processable data such as geocoordinates, contact information, calendar data or keywords enrich the code behind Weblog entries which makes them better searchable. One example is the Word-Press plug-in FOAF (Friend of a Friend) output which analyses Weblog entries and exports identified relationships as FOAF model. Another example is the WordPress plug-in Yahoo!Shortcuts which detects named entities such als locations, persons, organisations, or products within Weblog entries and enriches these entities semantically. User can then add materials such as photos to these entities which makes the information even richer. If an Ontology structures the additional data, we talk about semantic blogging.

Also Community Management can be supported by utilising semantic technologies. Identifying and annotating actors and relations among them and laying this information down in semantic web suitable formats helps finding people with complementary or similar competencies. This can be of interest when someone has to find a co-author or an expert for a joint project proposal. Also, suggestions for possibly interesting communities can be made on this basis. Fravity is such software. It analyses user profiles and depending on the number of common friends users are represented more or less connected to each other. Another approach is followed by Twine. This software analyzes content that a user flags important during her daily work. These contents are enriched with semantic information and are interpreted as interest profiles. These profiles are matched so that recommendations concerning content, people or topics can be generated. A well known project on this topic is Socially Interlinked Online Communities by DERI7. In this project an Ontology was developed including the central concepts of online communities such as user, role or post and describing the relations among them. By this coherent description various online communities, even based on different tools such as Weblogs, Chats or Forums are connected to each other. A query would span all these communities and tools yielding e.g. all community statements matching the query.

\subsection{Social Semantic Technologies Applied to Learning and Knowledge Transfer}

Since it is only about two years that Social Semantic Web applications have come up, according installations in organizations are not common. Just since most recently companies have become familiar with utilizing Social Software. They are not yet familiar with semantic technologies, and even to a much lesser extent with Social Semantic Technologies. This is

${ }^{7} \mathrm{http}: / /$ sioc-project.org/ 
why currently we can provide only possible scenarios but no real world examples. However, research addressing Social Semantic Technologies is under way. In (Blumauer et al., 2006) the situation of Semantic Technologies has been analysed and in a former and a current research project the authors are concerned with the application of a Semantic Wiki in the context of research communities.

Supporting new employees

Consider an employee who is new to the company: in addition to demonstrating her competence by working in a project, she faces the challenge of learning about the company. A lot of questions are open at the beginning: Which topics does the company deal with? Which partners does the company have? Which colleagues are working on what topics? What kind of projects does the company usually conduct? Usually, the new employee learns about all these things in a step-wise fashion. She reads project reports, talks to colleagues, participates in meetings. Usually, it takes weeks to months until a new employee is familiar with the company concerns. However, it is in the interest of the employer to bring an employee to its full potential as soon as possible. And also the employee can be more productive if she has a complete picture about her working environment. A comprehensive overview about all this information would support this. In order to optimize that overview, in addition to information elements it should also include relations between them. These relations would state the type of connection between information elements. A sound understanding can be built on this basis. Of course, relevant information often is available in knowledge management systems or similar systems. However, these systems usually suffer from rigidity and information elements are neither connected to each other within one system nor across systems. It is a time and resource intensive task finding out which information is archived where and how information elements relate. A Semantic Wiki could be one alternative of preparing company related information in an easy to navigate way. However, the utilization of a Semantic Wiki requires underpinning content with a knowledge structure that meets the individual purpose. Concepts such as project, person, partner, area, and topic as well as relationships among them could make up such a structure. By specifying relations among these topics the accessibility of information would be enhanced. Example relations are: person works-in project, person knows-about topic, or area deals-with topic. A new employee who searches for a certain person would not only find the person and artefacts the person produced, but additional information about that person, namely that she works-in certain projects or knows-about certain topics would be delivered automatically.

Sharing knowledge across projects

Consider an organization which uses Weblogs for documentation of project work of course excluding legal information such as contracts etc,. Each Weblog includes information about involved partners, personnel, topics, results and publications. These Weblogs serve several functions. All people involved in the project contribute and find information about the course of the project, workpackages, deadlines, outputs, as well as people and partners involved. The executive manager uses the Weblogs for getting a quick overview about the current work progress. Concerning manager tasks such as strategic planning she uses the Weblogs for identifying common interests among partners involved in different projects or trend topics. And sales staff searches the Weblogs for information that can be used for marketing such as partner companies, software for demonstration or publications. This would help them to better understand the various topics which in turn improves the 
communication towards potential customers. For all of these groups searching the Weblogs for the individually relevant information is a resource intensive task. For the project staff it is difficult to find out which other projects dealt with similar topics or whether partners were involved also in other projects. Information about that could be important for overcoming knowledge deficits or difficulties with partners. For the executive manager it would be an effort to find out which partners work on similar topics within the projects and thus could be linked together for a further, more comprehensive project. This knowledge would be important for talking to the partners and convincing them about the importance of the collaboration. And sales staff would have difficulties finding out which projects had marketable results such as software demonstrations to be used for sales presentations. As introduced in the previous section the solution could lay in enriching the Weblog with semantics. This could be achieved by relating the central concepts used in the context of project work to each other. Therefore a meaningful semantic structure is required. As in the previous example, this structure could include relations such as partner deals with topic, project is about topic, or person works in project. Defining the structure would be less of a difficulty. First of all concepts must be identified based on instances in the entries. Part of the concepts such as person, organization, or products could be automatically identified by named entity recognition. However, the concept result referring to software demos, products or services cannot be found out automatically. The same is true for the concept output referring to publications of presentations. Such concepts would have to be indicated by the authors themselves. They are requested to enrich the text with corresponding $\mathrm{xml}$ tags which could be used by the machine. If then the executive manager would for example search for a topic she would also get the information which partners deal with this topic or which projects are concerned with this topic. From this information she could infer which partners are interested in the same topic and thus might cooperate in a subsequent project. Or she could identify side issues. On this basis she could further research whether these topics are emergent themes or themes which would require less attention in the future.

\section{Conclusion}

This article showed there are three technological streams delivering great benefits for new ways of learning and knowledge transfer, i.e. Social Software, Semantic Technologies and Social Semantic Technologies. The real world examples and scenarios contributed to a better understanding for how the technologies can support new ways for learning and knowledge transfer. Our assessment is that currently the usefulness of Social Software is highest. Its advantages are the rather simple applications which can be used to solve a variety of problems referring to development, storage, organization, and distribution of information. Semantic technologies have their strengths in the structured organization and retrieval of information. By organizing information according to coherent structures relevant information can easily be retrieved and related information can be provided which makes relations visible to users which would remain invisible otherwise. However, for benefiting from semantic technologies organizations are required to structure their business domain and to reduce information to a manageable number of concepts. Also, the idea behind semantic technologies may sound a bit complex for managers who have to decide whether a tool is used or not. Finally, semantic technologies are often considered to be in a pre-mature experimental status yet. This is also the reason, why social semantic technologies might have 
the same problem. However, maybe they could be exploited for evangelizing semantic technologies. Since Social Software supports the production of user generated content, it becomes clear that vast amounts of content can be produced at high speed bearing the risk of little usage unless appropriate (semantic) technologies are in place. At the same time it is clear that the produced information is of high relevance for the organizations, since it reflects employee knowledge which otherwise could not be leveraged but is very useful. Ex ante structures cannot be defined if it remains unclear who will contribute which knowledge. And the manual definition of ex post structures is a time- and resourceconsuming task. But if in some way structure could be generated automatically the value of semantic technologies would be uncovered.

\section{Acknowledgement}

The Know-Center is funded within the Austrian COMET Program - Competence Centers for Excellent Technologies - under the auspices of the Austrian Federal Ministry of Transport, Innovation and Technology, the Austrian Federal Ministry of Economy, Family and Youth and by the State of Styria. COMET is managed by the Austrian Research Promotion Agency FFG.

\section{References}

Blumauer, A., Dösinger, G., Fundneider, T. \& Meinl, P. (Eds.). (2006). Semantic Technologies Showcase - The Austrian Situation. OCG Report, October 2006.

Brakeley, H., Cheese, P. \& Clinton, D. (2004). The High Performance Workforce Study 2004. Accenture.

Chief Learning Officer. 2007 CLO Business Intelligence Industry Report. Management Summary. http://www.clomedia.com/biireport/BZ_2007_Summary_r2.pdf

Colucci, S., Di Noia, T., Di Schiascio, E., Donini, F.M. \& Ragone, A. (2007). A Semantic-based Integrated Solution to Personnel and Learning Needs. Proceedings of I-KNOW'07, September 5-7, 2007, Graz, Austria.

Cross, J. (2003). Informal Learning: A Sound Investment. Chief Learning Officer Magazine, October 2003. http://www.clomedia.com/content/templates/clo_col_effectivenes s.asp?articleid=277\&zoneid $=104$

Cross, J. (2007). Informal YouTubing again. http://informl.com/2007/01/16/informalyoutubing-again/

Daconta, M. C., Obrst, L. J. \& Smith, K. T. (2003). The Semantic Web: A Guide to the Future of XML, Web Services, and Knowledge Management, John Wiley \& Sons.

Gruber, T. R. (2008). Ontology. In L. Liu \& M.T. Özsu (Eds.): Encyclopedia of Data-base Systems, Springer, Berlin - Heidelberg.

Hain, S. \& Schopp, B. Unternehmensinterner Multiblog der Namics AG. In A. Back, N. Gronau, K. Tochtermann (Hrsg.). Web 2.0 in der Unternehmenspraxis Grundlagen, Fallstudien und Trends zum Einsatz von Social Software. Oldenbourg Wissenschaftsverlag, ISBN 978-3-486-58579-7, München.

Jameson, A. (2001). Modeling Both the Context and the User. Personal and Ubiquitous Computing, 5(1), pp. 29-33, Springer, London. 
Klemke, R. (2002). Modelling Context in Information Brokering Processes. Dissertation, Rheinisch-Westfälische Technische Hochschule Aachen.

Ley, T., Ulbrich, A. W., Scheir, P., Lindstaedt, S. N., Kump, B. \& Albert, D. (2007). Modelling Competencies for Supporting Work-Integrated Learning in Knowledge Work. Journal of Knowledge Management.

Ley, T., Kump, B., Ulbrich, A., Scheir, P. \& Lindstaedt, S. N. (2008). A Competence-based Approach for Formalizing Learning Goals in Work-integrated Learning. EDMedia'08.

Lindstaedt, S.N. et al. (2005). Advanced Process-Oriented Self-Directed Learning Environment APOSDLE. Integrated Project Proposal, IST Call 4, FP6-2004-IST-4, 2005.

Lindstaedt, S. N. \& Ulbrich, A. (2006). Integration von Arbeiten und Lernen - Kompetenzentwicklung in Arbeitsprozessen. T. Pellegrini \& A. Blumauer (Eds.). Semantic Web - Wege zur vernetzten Wissensgesellschaft, pp. 147-160, Springer, Berlin Heidelberg.

Magnus, S. \& Hatz, M. (2008). Podcasts in der Vertriebsschulung bei Opel. In A. Back, N. Gronau, K. Tochtermann (Hrsg.). Web 2.0 in der Unternehmenspraxis Grundlagen, Fallstudien und Trends zum Einsatz von Social Software. Oldenbourg Wissenschaftsverlag, ISBN 978-3-486-58579-7, München.

McAfee, A. (2008). Did My Students Drink the Kool-Aid. In: Harvard Business School Faculty Blog, Harvard Business School, 2008.

http://blog.hbs.edu/faculty/amcafee/index.php/faculty_amcafee_v3/did_my_st udents_drink_the_kool_aid/

Mielke, M., Schulte, M. \& Neus, A. (2008). Wissensmanagement mit Social Software in der Managementberatung: Das Wiki-Prinzip der Selbstorganisation. In A. Back, N. Gronau, K. Tochtermann (Hrsg.). Web 2.0 in der Unternehmenspraxis Grundlagen, Fallstudien und Trends zum Einsatz von Social Software. Oldenbourg Wissenschaftsverlag, ISBN 978-3-486-58579-7, München.

O'Reilly, T. (2007). What Is Web 2.0. Design Patterns and Business Models for the Next Generation of Software. O'Reilly Media, Inc. www.oreillynet.com/pub/a/oreilly/tim/news/2005/09/30/what-is-web-20.html.

Pellegrini, T. \& Blumauer, A. Was ist das Social Semantic Web? Magazin der Österreichischen Gesellschaft für Künstliche Intelligenz, 2007, 26, 19-23.

Pellegrini, T. \& Blumauer, A. (2008). Social Semantic Web: Die Konvergenz von Social Software und semantischen Technologien. In A. Back, N. Gronau, K. Tochtermann (Hrsg.). Web 2.0 in der Unternehmenspraxis - Grundlagen, Fallstudien und Trends zum Einsatz von Social Software. Oldenbourg Wissenschaftsverlag, ISBN 978-3486-58579-7, München.

Raybould, B. (2000). Performance Support Engineering, Part One: Key Concepts. Ariel PSE Technology, 2000, ISBN-10 0970502206.

Robinson, D.G. (2003). Skill and Performance: They are not equal. Apartment Professional Magazine, 2003.

Sauermann, L., van Elst, L. \& Dengel, A. (2007). PIMO - A Framework for Representing Personal Information Models. Proceedings of I-MEDIA'07 und I-SEMANTICS'07, September 5-7, 2007, Graz, Austria. 
Schaffert, S., Bischof, D., Bürger, T., Gruber, A., Hilzensauer, W. \& Schaffert, S. (2006). Learning with Semantic Wikis. In M. Völkl (Ed.). First Workshop SemWiki2006 From Wiki to Semantics, 2006, 109-123. http:/ / www.eswc2006.org/technologies/ usb/proceedings-workshops/eswc2006-workshop-semantic-wikis.pdf\#page=117

Scheir, P., Ghidini, C. \& Lindstaedt, S.N. (2007). Improving Search on the Semantic Desktop Using Associative Retrieval Techniques. Proceedings of I-MEDIA'07 und ISEMANTICS'07, September 5-7, 2007, Graz, Austria.

Schmidt, A. (2004). Kontextgesteuertes Lernen in Unternehmensumgebungen: Der Leanring-In-Process-Ansatz. Deutsche e-Learning Fachtagung der Gesellschaft für Informatik, 2004, Paderborn.

Sicilia, M. (2005). Ontology-Based Competency Management: Infrastructures for the Knowledge-Intensive Learning Organization. In M. Lytras \& A. Naeve (Eds.). Intelligent Learn-ing Infrastructure for Knowledge Intensive Organizations: A Semantic Web Perspective, Information Science Publishing, 2005.

Stocker, A., Granitzer, G., Hoefler, P. \& Tochtermann, K. (2008). Towards a Framework for Social Web Platforms: The Neurovation Case. International Conference on Internet and Web Applications and Services, 2008.

Tochtermann, K. \& Granitzer, G. (2008). The Long Way towards Workplace-Integrated Learning. Proceedings of The 8th IEEE International Conference on Advanced Learning Technologies, July 1 - 5, 2008, Santander, Cantabria, Spain. 


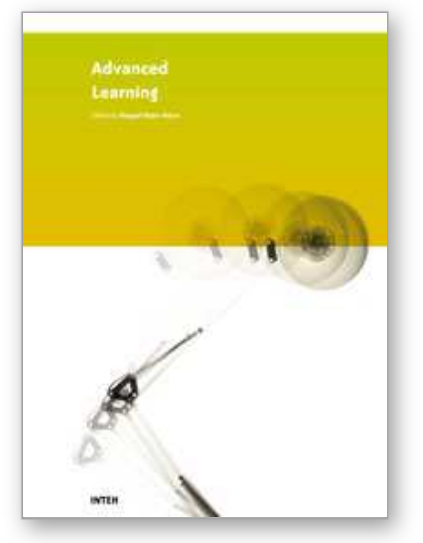

\author{
Advanced Learning \\ Edited by Raquel Hijn-Neira
}

ISBN 978-953-307-010-0

Hard cover, 444 pages

Publisher InTech

Published online 01, October, 2009

Published in print edition October, 2009

The education industry has obviously been influenced by the Internet revolution. Teaching and learning methods have changed significantly since the coming of the Web and it is very likely they will keep evolving many years to come thanks to it. A good example of this changing reality is the spectacular development of eLearning. In a more particular way, the Web 2.0 has offered to the teaching industry a set of tools and practices that are modifying the learning systems and knowledge transmission methods. Teachers and students can use these tools in a variety of ways aimed to the general purpose of promoting collaborative work. The editor would like to thank the authors, who have committed so much effort to the publication of this work. She is sure that this volume will certainly be of great help for students, teachers and researchers. This was, at least, the main aim of the authors.

\title{
How to reference
}

In order to correctly reference this scholarly work, feel free to copy and paste the following:

Gisela Granitzer, Armin Ulbrich, Klaus Tochtermann and Reinhard Willfort (2009). New Ways for Learning and Knowledge Transfer Using Social Semantic Technologies, Advanced Learning, Raquel Hijn-Neira (Ed.), ISBN: 978-953-307-010-0, InTech, Available from: http://www.intechopen.com/books/advanced-learning/new-waysfor-learning-and-knowledge-transfer-using-social-semantic-technologies

\section{INTECH}

open science | open minds

\section{InTech Europe}

University Campus STeP Ri

Slavka Krautzeka 83/A

51000 Rijeka, Croatia

Phone: +385 (51) 770447

Fax: +385 (51) 686166

www.intechopen.com

\section{InTech China}

Unit 405, Office Block, Hotel Equatorial Shanghai

No.65, Yan An Road (West), Shanghai, 200040, China

中国上海市延安西路65号上海国际贵都大饭店办公楼405单元

Phone: +86-21-62489820

Fax: $+86-21-62489821$ 
(C) 2009 The Author(s). Licensee IntechOpen. This chapter is distributed under the terms of the Creative Commons Attribution-NonCommercial-ShareAlike-3.0 License, which permits use, distribution and reproduction for non-commercial purposes, provided the original is properly cited and derivative works building on this content are distributed under the same license. 